\title{
Correction to: Dietary Supplementation of Walnut Partially Reverses 1-Methyl-4-phenyl-1,2,3,6-tetrahydropyridine Induced Neurodegeneration in a Mouse Model of Parkinson's Disease
}

\author{
Musthafa Mohamed Essa ${ }^{1,2}$. Selvaraju Subash ${ }^{1}$. Chinnasamy Dhanalakshmi ${ }^{3}$. Thamilarasan Manivasagam ${ }^{3}$. \\ Samir Al-Adawi ${ }^{2,4}$. Gilles J. Guillemin ${ }^{5}$. Arokiasamy Justin Thenmozhi ${ }^{3}$
}

Published online: 18 October 2019

(c) Springer Science+Business Media, LLC, part of Springer Nature 2019

\section{Correction to: Neurochem Res (2015) 40:1283-1293 https://doi.org/10.1007/s11064-015-1593-2}

The original version of this article unfortunately contains an error in Fig. 2a (4th image for walnut). This has been corrected by publishing this erratum.

The correct version of the 4th image in Fig. 2a is given below.

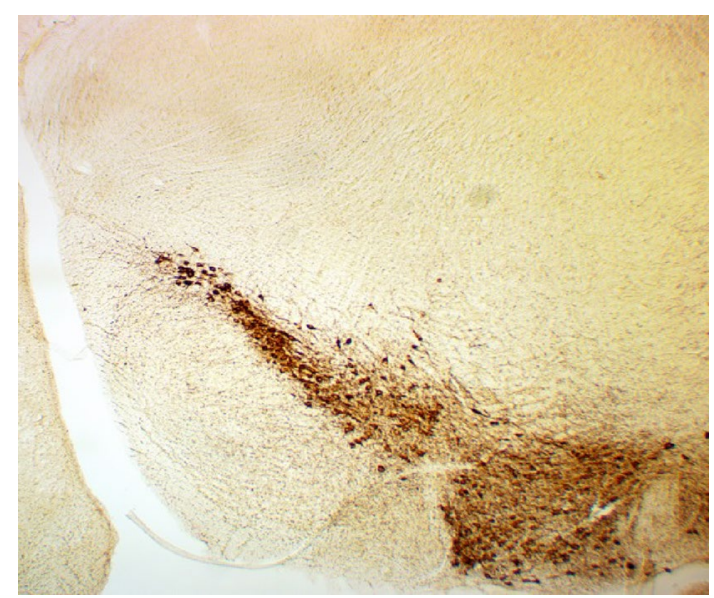

Publisher's Note Springer Nature remains neutral with regard to jurisdictional claims in published maps and institutional affiliations.

The original article can be found online at https://doi.org/10.1007/ s11064-015-1593-2.

Musthafa Mohamed Essa

drmdessa@gmail.com; drmdessa@squ.edu.om

1 Department of Food Science and Nutrition, College of Agricultural and Marine Sciences (CAMS), Sultan Qaboos University, P.O. 34, Al-Khoud, Muscat 123, Sultanate of Oman

2 Aging and Dementia Research Group, Sultan Qaboos University, Muscat, Sultanate of Oman

3 Department of Biochemistry and Biotechnology, Faculty of Science, Annamalai University, Annamalainagar, Tamilnadu, India

4 Department of Behavioral Medicine, College of Medicine and Health Sciences, Sultan Qaboos University, Muscat, Sultanate of Oman

5 Neuropharmacology Group, ASAM, Macqurie University, Sydney, NSW, Australia 